\title{
Enantioselective Synthesis of Cyclic Nitrones and Oxime Ethers by Chemoselective Allylic Alkylation of Oximes
}

\author{
Tobias Sandmeier, Erick M. Carreira* \\ ETH Zürich, Vladimir-Prelog-Weg 3, HCl, 8093 Zürich, Switzerland
}

\begin{abstract}
The enantio- and chemoselective iridium-catalyzed $N$ - and $O$-allylation of oximes is described for the first time. Kinetic resolution in an intramolecular setting provides access to cyclic nitrones, oxime ethers and enantioenriched aliphatic allylic alcohols. Salient features of this transformation are its ability to employ $E / Z$-isomeric mixtures of oxime starting materials convergently, high functional group tolerance, and divergent $\mathrm{N}$ - or $\mathrm{O}$-allylation by choice of the reaction conditions. The implementation of $\mathrm{N}$-allylation/1,3-dipolar cycloaddition reaction cascades furnish tricyclic oxazolines in highly enantio- and diastereoselective fashion. Expansion of this approach to the selective allylation of hydrazones allows enantioselective preparation of azomethine imines. The synthetic utility of the approach is demonstrated by the efficient, formal syntheses of glycoprotein GP IIb-IIla receptor antagonist $(-)$-roxifiban and marine natural product (+)-halichlorine.
\end{abstract}

\section{Introduction}

Nitrones are valuable intermediates for the synthesis of nitrogen containing pharmaceuticals, ${ }^{1}$ complex natural products, ${ }^{2}$ functional materials, ${ }^{3}$ and bioconjugates. ${ }^{4}$ They can function as electrophiles, ${ }^{5,6}$ as directing groups in $\mathrm{C}-\mathrm{H}$ fuctionalizations, ${ }^{7}$ and as dipoles in 1,3-dipolar cycloadditions. ${ }^{8}$ The latter stand out as a particularly important tools for synthetic chemists as they enable concomitant formation of $\mathrm{C}-\mathrm{C}$ and $\mathrm{C}-\mathrm{O}$ bonds, heterocycle syntheses, and approaches to $\beta$-lactams. ${ }^{9}$ In particular, intramolecular 1,3-dipolar cycloadditions forge multiple rings in a single step and have found widespread utility in complex target synthesis. ${ }^{10}$

Racemic, cyclic nitrones are featured as key intermediates in numerous, classic syntheses of fused rings and/or spirocycles. ${ }^{11}$ Some of the most famous examples include syntheses of cocaine and a variety of poison dart frog toxins. ${ }^{12}$ The discovery of synthetically useful, asymmetric, catalytic approaches to optically active, cyclic nitrones stands to significantly impact the evolution of strategic considerations in complex synthesis. Herein, we report the enantioselective synthesis of 5-, 6- and 7-membered cyclic nitrones by enantioselective $N$-allylation of hydroxy oximes under dual catalyst control involving iridium(I) and Brønsted acids (Scheme 1A). Interestingly, in the presence of Lewis acids and base under otherwise identical conditions the same iridium catalyst furnished cyclic oxime ether products, resulting from enantioselective $O$-allylation. We applied the latter to the formal synthesis of DuPont's (-)-roxifiban, a glycoprotein receptor antagonist. ${ }^{13}$ Implementation of the former in tandem $\mathrm{N}$-allylation/dipolar cycloaddition sequence furnished oxazatriquinanes in a highly stereo-controlled fashion (Scheme 1B), which is showcased in the formal synthesis of (+)-halichlorine, an inhibitor of vascular cell adhesion protein $1 .{ }^{14}$

There have been a number of key developments in asymmetric catalysis for the preparation of acyclic, optically active nitrones from oximes via intermolecular olefin hydroamination. Zhang has reported copper/bisphosphine- catalyzed diastereo- and enantioselective hydroamination of cyclopropenes using oximes as nucleophiles, furnishing $\mathrm{N}$-cyclopropyl substituted nitrones. ${ }^{15}$ Kobayashi has described enantioselective conjugate addition of aldoximes to various Michael acceptors using a chiral Lewis acid combined with single-walled carbon nanotubes and a surfactant in aqueous media. ${ }^{16}$ Breit documented the rhodium-catalyzed chemo- and enantioselective hydroamination of symmetrical diaryl or dibenzyl oximes to allenes, providing access to $\mathrm{N}$-allylated nitrones. ${ }^{17}$ By contrast, there is a paucity of catalytic, enantioselective approaches to cyclic nitrones. 
Scheme 1. Chemodivergent, Enantioselective Synthesis of Cyclic Nitrones and Oxime Ethers.

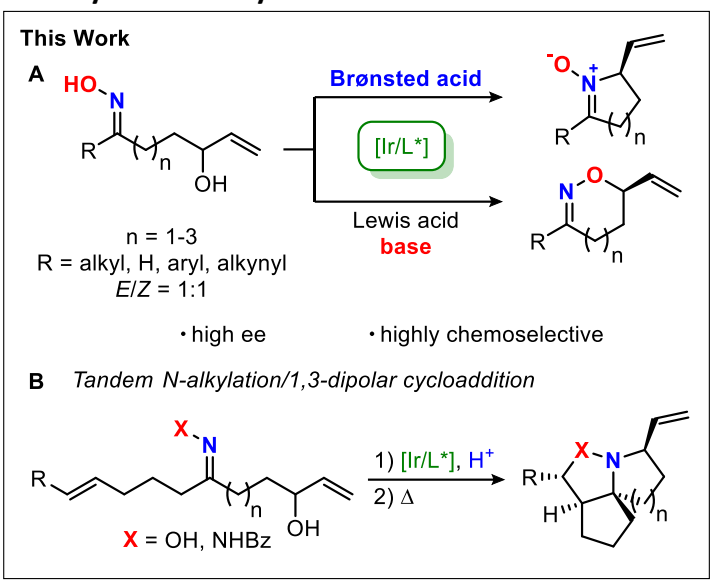

To date, only one example of catalytic, enantioselective synthesis of cyclic nitrones has appeared in the literature (Chart 1). In 2019, Zhang reported the intramolecular hydroamination of olefins using a copper/bisphosphine catalyst. ${ }^{18}$ The method prescribes the use of oximes derived from $\gamma, \delta$-unsaturated aryl ketones and furnishes 5 -membered nitrones. Optimal results were reported with substrates that incorporate aryl ketoximes with gem-dimethyl substitution at C $\alpha(\mathrm{R} 1=\mathrm{Me})$.

\section{Chart 1. Intramolecular hydroamination}

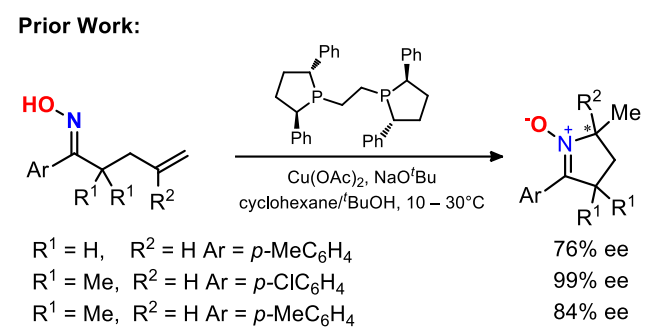

Based on our long-standing interest in iridium-catalyzed allylic substitution reactions, ${ }^{19,20}$ we sought to investigate chiral catalysts derived from $[\operatorname{Ir}(\operatorname{cod}) \mathrm{Cl}]_{2}$ and phosphoramidite-olefin ligands for the enantioselective synthesis of cyclic nitrones. In contrast to olefin hydroamination reactions, the use of secondary allylic alcohols for the $N$-functionalization of oximes introduces several complications (Scheme 2). In the most general process, the starting material employed is a mixture of 4 stereoisomers because the substrate allylic alcohols are racemic and include oxime geometric isomers (Scheme 2). At the outset of our investigations, the compatibility of chiral iridium catalysts when confronted with this mixture was uncertain, because both olefins and oximes may be ligands for iridium. ${ }^{21}$ Additionally, as oximes are ambident nucleophiles, ${ }^{22}$ it was not clear whether $\mathrm{O}$ versus $\mathrm{N}$-cyclization would be simply determined by oxime geometry $\left(\mathbf{I} \rightarrow \mathbf{2}\right.$ and II $\rightarrow \mathbf{3}$ ) or alternatively by product ring size (e.g., in Scheme $2: \mathbf{2}$ versus $\mathbf{3}$ ). ${ }^{23,24}$ In the ideal process, a Curtin-Hammet scenario ${ }^{25,26}$ would allow both diastereomers of the oxime starting material to converge into a single cyclic nitrone or cyclic oxime ether products. Finally, if $O$-allylation leading to $\mathbf{3}$ is reversible, an additional competing pathway could operate that interconverts $\mathrm{O}$ - and $\mathrm{N}$-cyclization products. ${ }^{20 f}$

Scheme 2. Intramolecular Enantio- and Chemoselective Allylation of Oximes.

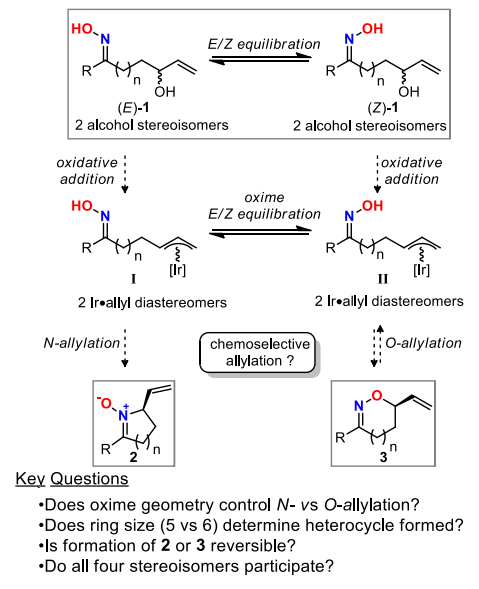




\section{Results and Discussion}

Reaction Development. We commenced our studies with allylic carbonate 1aa obtained as a 1:1 mixture of E/Z-oxime isomers (Table 1). Initial screening experiments (see Supporting Information) revealed efficient kinetic resolution of allylic carbonate 1aa with dichloroacetic acid as a promoter, furnishing cyclic nitrone $\mathbf{2 a}$ in $98 \%$ ee (entry 1 ). Notably, this reaction proceeded with complete chemoselectivity for the $\mathrm{N}$-allylated nitrone product. In order to streamline substrate synthesis and in the interest of atomeconomy, we next examined free allylic alcohols $1 \mathrm{ab}$

Table 1. Selected Optimization of Conditions ${ }^{a}$

(IIr(cod)

${ }^{a}$ Reactions run on $0.15 \mathrm{mmol}$ scale, yields were determined by ${ }^{1} \mathrm{H}$ NMR analysis of the unpurified reaction mixtures with 1,4dinitrobenzene as an internal standard, ee was determined using supercritical fluid chromatography (SFC) or HPLC.

as substrates. Lewis acids ( $\mathrm{Zn}(\mathrm{OTf})_{2}$, entry 2 ) and strong Brønsted acids (TFA, entry 3 ) combined with 1ab resulted in excellent chemoselectivity for $N$-allylation but only modest enantiomeric purity of either reisolated (S)-1ab or nitrone $2 \mathrm{a}$. The use of dichloroacetic acid enabled highly chemo- and enantioselective kinetic resolution of 1ab, giving nitrone $2 \mathbf{a}$ and allylic alcohol (S)-1ab in 98 and $>94 \%$ ee, respectively, as well as good yields (entry 4 ).

Over the course of the optimization studies, we also examined ligand $\mathbf{L}_{\mathbf{2}}$ in the reaction, which is usually used in iridium-catalyzed allylation reactions with activated electrophiles derived from the corresponding primary alcohols. ${ }^{27}$ Intriguingly, when linear carbonate 1 ac was utilized in combination with $\mathrm{Cs}_{2} \mathrm{CO}_{3}$ and iridium(I) $\mathbf{L}_{2}$ complex, $O$-alkylated oxazepane product $3 a$ was obtained exclusively ( $71 \%$ yield, $61 \%$ ee, entry 5$).{ }^{28}$ We next employed secondary allylic alcohol 1 ab together with $\mathrm{L}_{1}, \mathrm{Cs}_{2} \mathrm{CO}_{3}$. and $\mathrm{Zn}(\mathrm{OTf})_{2}$ (entry 6). Under these conditions exclusive formation of $3 a$ was again observed, albeit with low yield. This result nicely demonstrates that the use of the same catalyst, starting material, and solvent can furnish either $\mathbf{2 a}$ or $\mathbf{3 a}$ selectively by excluding or adding $\mathrm{Cs}_{2} \mathrm{CO}_{3}$. Further screening of reaction conditions (see Supporting Information) led to the identification of Sc(OTf) $)_{3}$ as the ideal promoter for the formation of cyclic oxime 3 a from highly chemoselective $O$-allylation of 1 ab via kinetic resolution (47\% yield, $96 \%$ ee, entry 7 ).

Substrate scope. With optimized conditions for the chemo- and enantioselective synthesis of cyclic nitrones, we focused on exploring substrate scope (Table 2). Ketoxime $\mathbf{1 b}\left(R=M e, R^{\prime}=H, n=2\right)$, was readily converted to cyclic nitrone $\mathbf{2 b}$ with excellent enantio- and chemoselectivity ( $98 \%$ ee, $N / O>20: 1)$. $E / Z$-mixtures of ketoximes $(E / Z=1: 1$ to $1.5: 1)$ bearing longer and bulkier aliphatic sidechains also furnished the expected products (2c and $\mathbf{2 d}$ ). In addition, we could establish that different functional groups were well tolerated, leading to products incorporating benzyl-substitution (2e), acetals (2f) and silyl ethers (2g) in $\mathbf{4 1 - 4 6 \%}$ yields ( $\max =50 \%), 98-99 \%$ ee, and $>20: 1 \mathrm{~N}-/ O$ - chemoselectivity. Furthermore, gem-dimethyl substituted nitrone (2h) was accessed in $46 \%$ yield and $99 \%$ ee. Alkynyl nitrone $\mathbf{2} \mathbf{i}$ was prepared in $93 \%$ ee, and nitrones $\mathbf{2} \mathbf{j}-\mathbf{I}$ were synthesized in $95 \%$ ee, $95 \%$ ee, and $92 \%$ ee, respectively. 
Table 2. Substrate Scope of the Intramolecular $N$-Allylation of Oximes ${ }^{a}$

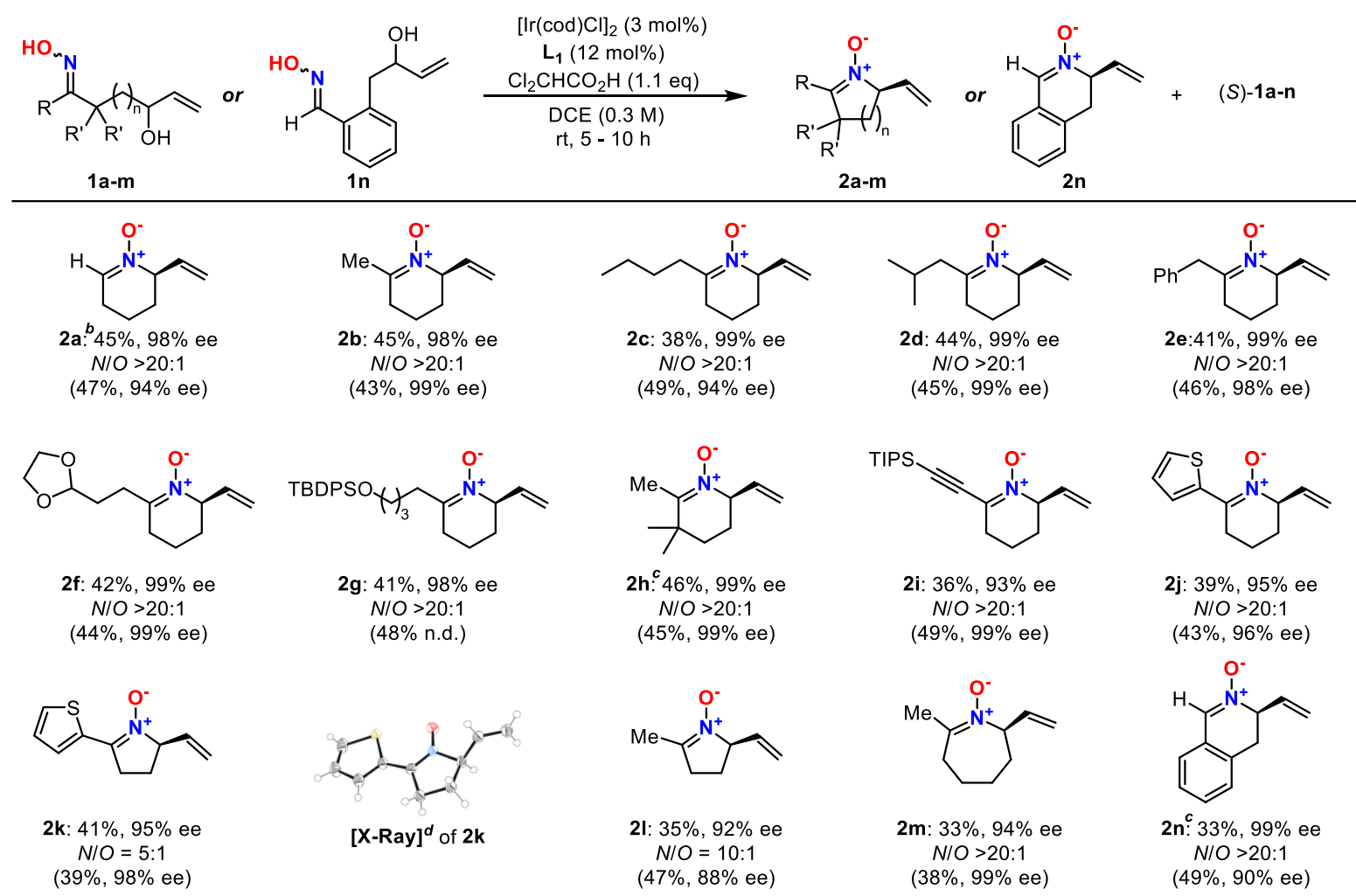

${ }^{a}$ Reactions run on $0.3 \mathrm{mmol}$ scale. Numbers in parentheses refer to recovered starting material 1. Yields refer to isolated products after flash column chromatography. Enantiomeric excess values (ee) were determined by HPLC, SFC or GC analysis on a chiral stationary phase. The ratio of $\mathrm{N}$ - vs. $\mathrm{O}$-alkylation $(\mathrm{N} / \mathrm{O})$ was determined by ${ }^{1} \mathrm{H}$ NMR analysis of the unpurified reaction mixtures. ${ }^{b}$ Yields determined using ${ }^{1} \mathrm{H}$ NMR spectroscopy with 1,4-dinitrobenzene as an internal standard. ${ }^{C}$ Reaction run at $0{ }^{\circ} \mathrm{C}$. ${ }^{d} \mathrm{Thermal}$ ellipsoids displayed at $50 \%$ probability level.

Interestingly, for the reaction of substrate $\mathbf{1 k},{ }^{1} \mathrm{H}-\mathrm{NMR}$ analysis of unpurified products revealed a 5:1 ratio of $N / O$-allylation products, marking the first time we observe $O$-cyclization under Brønsted acidic conditions. Notably, in addition to 5- and 6- membered ring nitrones, 7-membered azepane-derived nitrone $\mathbf{2 m}$ was accessed in $94 \%$ ee, without any formation of the oxazocane. Finally, cyclization of aromatic aldoxime $\mathbf{1}$ f furnished dihydroisoquinoline $N$-oxide $\mathbf{2 n}$ in $99 \%$ ee and with complete chemoselectivity for $N$ alkylation. Notably, this kinetic resolution is highly efficient with selectivity factors $s>50$ for all substrates. ${ }^{29}$

Subsequent experimentation was aimed at preparing tricyclic ring systems via iridium-catalyzed enantioselective oxime $\mathrm{N}$ allylation followed by intramolecular 1,3-dipolar cycloaddition. Grigg, ${ }^{30}$ Stockman, ${ }^{12 c, 31}$ and Coldham ${ }^{32}$ have reported a series of cascade reactions of racemic nitrone intermediates, which are accessed by aza-Michael addition or $N$-alkylation of oximes and undergo intramolecular 1,3-dipolar cycloaddition with olefins. ${ }^{33}$ Although these reactions proceed with excellent diastereocontrol, catalytic enantioselective versions have remained elusive, and to the best of our knowledge are lacking precedence. Therefore, we prepared oxime $\mathbf{1 0}$ and subjected the mixture of four stereoisomers to the optimized reaction protocol, whereupon cycloadduct 4 was isolated in $43 \%$ yield and $94 \%$ ee, as a single diastereomer (Scheme 3 ). Reductive cleavage of the $\mathrm{N}-\mathrm{O}$ bond gave spirocyclic amino alcohol $\mathbf{5}$ in $91 \%$ yield. X-ray crystallographic analysis of $\mathbf{5 ~ H C l}$ allowed unambiguous assignment of the absolute configuration. Similarly, reaction of $1 \mathrm{p}$ afforded oxazatriquinane 6 as a single product in $90 \%$ ee. To showcase the versatility of the method to access various ring scaffolds, we investigated the cyclization/dipolar cycloaddition sequence of oxime 1q. Gratifyingly, tricyclic oxazolidine 7 was obtained as a single stereoisomer in 99\% ee.

Scheme 3. Tandem $N$-alkylation/1,3-Dipolar Cycloaddition Reactions ${ }^{a}$ 

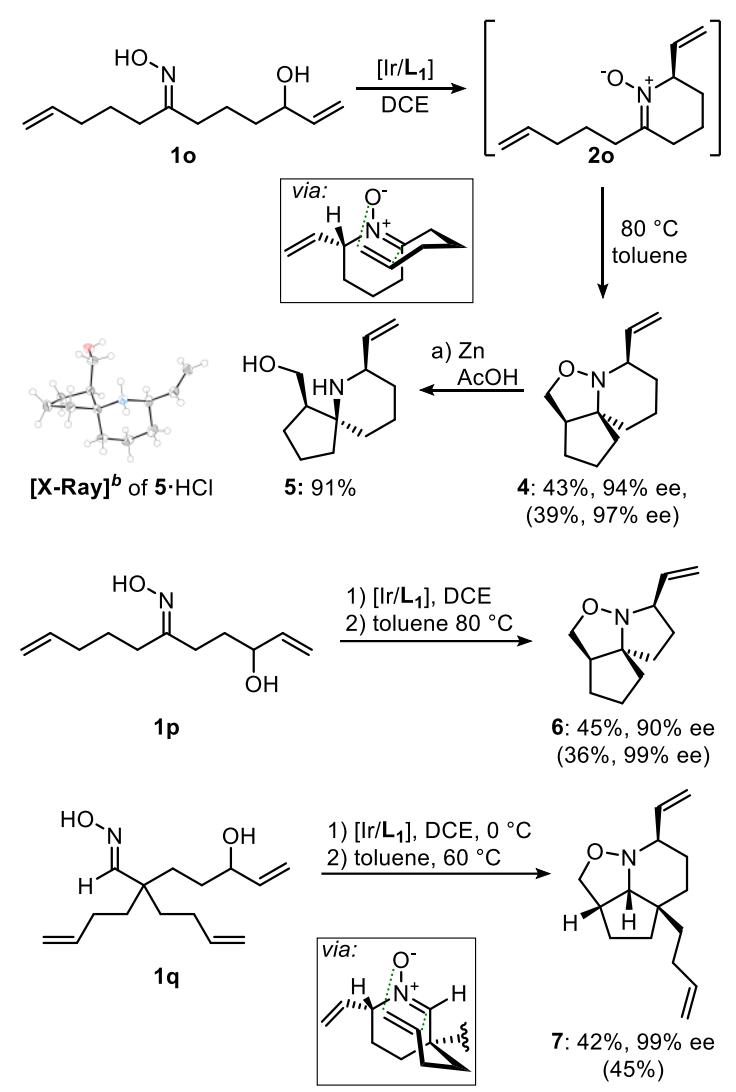

${ }^{a}$ For experimental details, see Table 2 and Supporting Information. Numbers in parentheses refer to recovered starting materials. All cycloadduct were formed in >20:1 d.r. Reagents and conditions: Cycloadditions carried out in degassed toluene (0.025 $\mathrm{M}$ ). (a) $\mathrm{Zn}, \mathrm{H}_{2} \mathrm{O} / \mathrm{AcOH}(2: 1), 60{ }^{\circ} \mathrm{C}$. ${ }^{b}$ Thermal ellipsoids displayed at $50 \%$ probability level. The chloride counterions were omitted for clarity.

Having established substrate scope for the iridium-catalyzed $\mathrm{N}$-allylation of oximes, we next focused on chemoselective $O$-allylation reactions, which furnishes cyclic oxime ethers, a common structural motive in pharmaceuticals and crop protection agents (Table 3)..$^{34}$ The optimized protocol for this transformation includes the combination of Lewis acid and $\mathrm{Cs}_{2} \mathrm{CO}_{2}$. It allowed facile preparation of six membered dihydrooxazine $\mathbf{3 b}$ with complete $O$-selectivity. Similarly, 2-thienyl dihydroxazine $\mathbf{3 c}$ was accessed in $44 \%$ yield and 95\% ee as a crystalline solid suitable for X-ray crystallographic analysis. Enantiopure allylic alcohol (S)-1m was reisolated in $41 \%$ yield. In addition to seven-membered oxazepane (3a) and six-membered oxazine (3b and $\mathbf{3 c}$ ) scaffolds, we examined the formation of five-membered isoxazolines. The optimized protocol for $\mathrm{O}$-allylation furnished $\mathbf{3 d}$ in $45 \%$ yield and $93 \%$ ee. Analogously, isoxazoline 3 e, was accessed in good yield and high enantiomeric purity (41\% yield, $92 \%$ ee).

Table 3. Substrate Scope of the Intramolecular O-Allylation of Oximes ${ }^{a}$

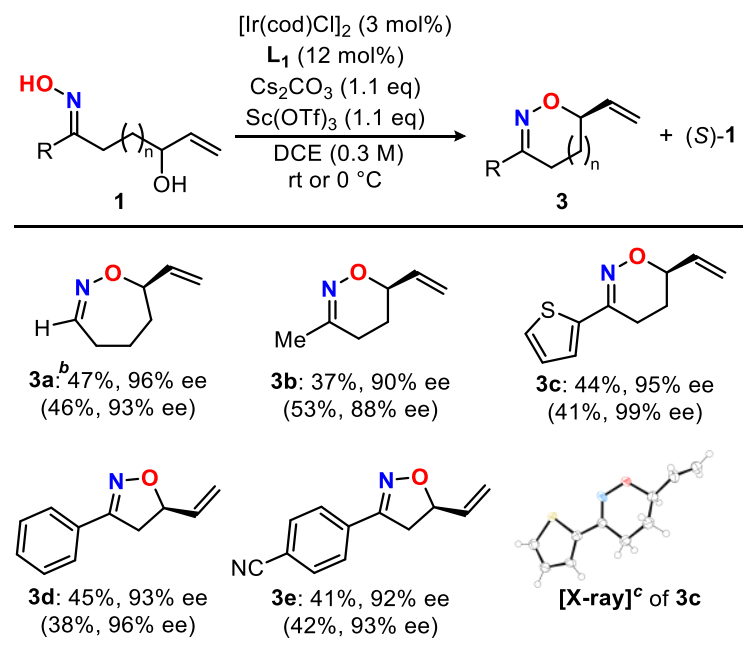


${ }^{a}$ Reactions run on $0.3 \mathrm{mmol}$ scale. Numbers in parentheses refer to recovered starting material 1. Yields refer to isolated products after flash column chromatography. Enantiomeric excess values (ee) were determined by HPLC, SFC or GC analysis on a chiral stationary phase. ${ }^{b}$ See table 1 , entry 7 for conditions. ${ }^{C}$ Thermal ellipsoids displayed at $50 \%$ probability level.

Azomethine Imines. To further expand the synthetic utility of the approach, we investigated the enantioselective synthesis of additional 1,3-dipoles, such as azomethine imines generated by enantio- and chemoselective $\mathrm{N}$-allylation under iridium catalysis (Scheme 4). ${ }^{35}$ Accordingly, treatment of hydrazone 8 with $\mathrm{Cl}_{2} \mathrm{CHCO}_{2} \mathrm{H}$ and the iridium complex derived from $\mathrm{L}_{\mathbf{1}}$ afforded a compound that was tentatively assigned as azomethine imine 9. Subsequent reduction with $\mathrm{NaBH}_{4}$ and recrystallization from $\mathrm{CH}_{2} \mathrm{Cl}_{2}$ afforded $\mathrm{X}$-ray quality crystals of hydrazide 10, which allowed confirmation of its structure and absolute configuration. Encouraged by this finding, we wondered whether hydrazones would participate in sequences involving $N$-allylation/dipolar cycloaddition. To this end, hydrazone 11 was prepared and subjected to the reaction conditions at $0{ }^{\circ} \mathrm{C}$ followed by heating to effect cycloaddition. This protocol provided tricyclic hydrazide 12 in $44 \%$ yield, $94 \%$ ee and 13:1 d.r. Sml $\mathrm{I}_{2}$-mediated cleavage of the $\mathrm{N}-\mathrm{N}$ bond afforded diamine 13, bearing a quaternary stereocenter (2-steps). These experiments clearly showcase that the strategy to build up optically active heterocycles via asymmetric $N$-allylation and cycloaddition can be expanded to additional 1,3-dipoles and thus paves the way for further developments.

\section{Scheme 4. Enantioselective Synthesis of Azomethine Imines ${ }^{a}$}

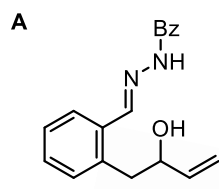

8

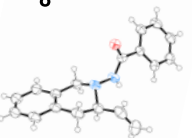

$[X-\text { ray }]^{b}$ of 10
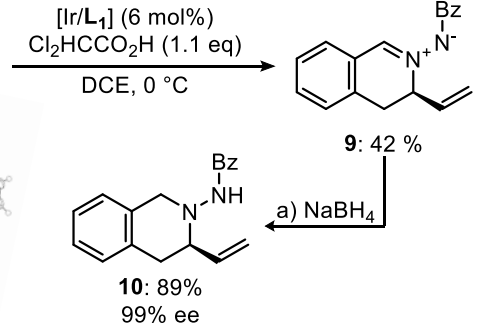

B

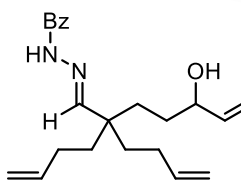

1) $\left[\mathrm{Ir} / \mathrm{L}_{1}\right](6 \mathrm{~mol} \%)$ $\mathrm{Cl}_{2} \mathrm{HCCO}_{2} \mathrm{H}(1.1 \mathrm{eq})$ 2) toluene $60^{\circ} \mathrm{C}$ 11

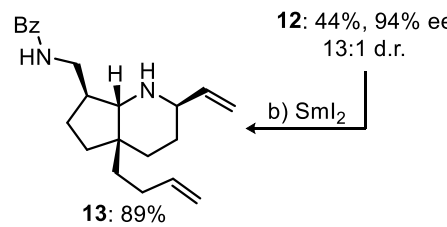

${ }^{a}$ Reactions run on $0.3 \mathrm{mmol}$ scale. Yields refer to isolated products after flash column chromatography. Reagents and conditions:

(a) $\mathrm{NaBH}_{4}, \mathrm{MeOH}$. (b) $\mathrm{Sml}_{2}, \mathrm{THF} / \mathrm{MeOH}$ (4:1). ${ }^{b}$ Thermal ellipsoids displayed at $50 \%$ probability level.

Synthetic Applications. To highlight the synthetic utility of this chemodivergent kinetic resolution process that gives rise to optically active nitrones, cyclic oxime ethers, and aliphatic allylic alcohols we examined the preparation of diverse optically active building blocks. To this end $\gamma$-hydroxy thienyl oxime $\mathbf{1 k}$ was chosen as a starting point (Scheme 5). Rhodium-catalyzed, oxime directed $\mathrm{C}-\mathrm{H}$ activation of enantioenriched $(S)$-1k furnished thienopyridine $\mathbf{1 4}$, a promising motif in drug discovery, ${ }^{36}$ without erosion of optical purity. Lithiation of dihydrooxazine $3 \mathrm{c}$ and subsequent trapping with allyl bromide allowed the selective installation of an additional stereocenter (15), ${ }^{37}$ showcasing the applicability of the method for the synthesis of highly substituted heterocycles. Having employed several nitrones as chiral 1,3-dipoles in diastereoselective cycloadditions (Scheme 3), we investigated their use as an electrophile in 1,2-additions. Therefore, $\mathbf{2} \mathbf{k}$ was treated with EtMgBr at $-78{ }^{\circ} \mathrm{C}$ to afford trisubstituted pyrrolidine 16 in $95 \%$ ee and 12:1 dr. These experiments highlight that starting from a single racemic compound (1k), a series of structurally diverse enantioenriched products can be accessed rapidly.

\section{Scheme 5. Functionalization of Products Derived from Oxime $\mathbf{1 k}^{a}$}




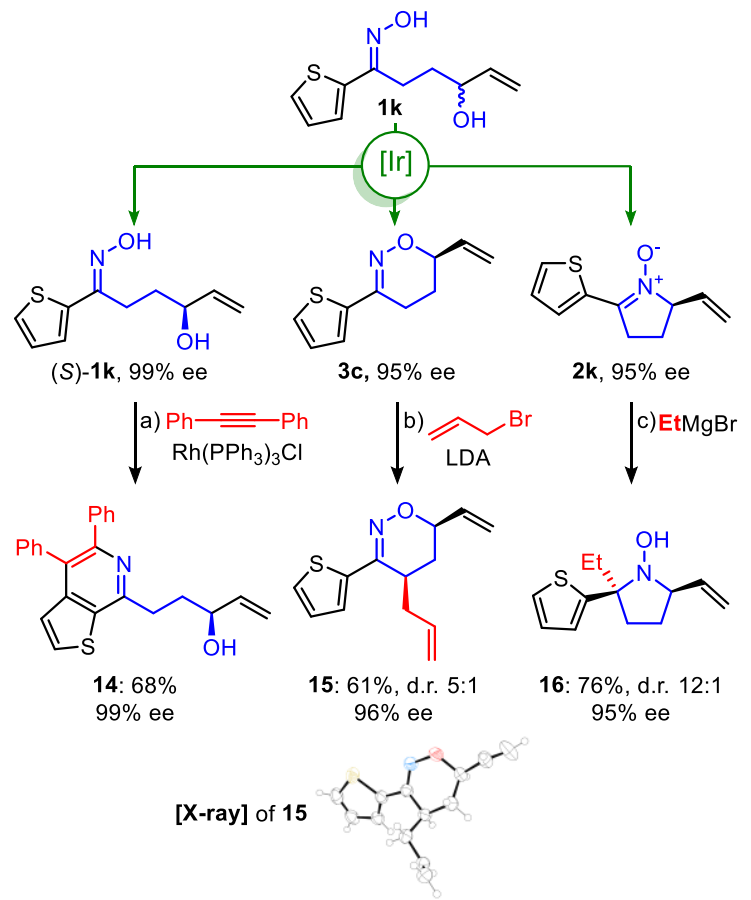

${ }^{a}$ Reagents and conditions: (a) $\mathrm{Rh}\left(\mathrm{PPh}_{3}\right)_{3} \mathrm{Cl}$ (3 mol\%), diphenylacetylene, toluene, $120^{\circ} \mathrm{C}$; (b) LDA, TMEDA, then allyl bromide, $\mathrm{THF},-78^{\circ} \mathrm{C}$ to $\mathrm{rt}$; (c) EtMgBr, THF, $-78^{\circ} \mathrm{C}$ to $\mathrm{rt}$. LDA = lithium diisopropylamide.

We next investigated the approach in the context of target-oriented synthesis. Initially we focused on the formal synthesis of (-)-roxifiban (18), a glycoprotein GP Ilb-IIla receptor antagonist investigated in clinical trials by DuPont for the treatment of various cardiovascular ailments including platelet adhesion (Scheme 6). ${ }^{13,38}$ Enantioenriched isoxazoline 3e was hydroborated and oxidized to the corresponding primary alcohol using 9-BBN and $\mathrm{H}_{2} \mathrm{O}_{2}$. Further oxidation with pyridinium dichromate (PDC) in anhydrous DMF cleanly afforded carboxylic acid $\mathbf{1 7}$ in $\mathbf{7 1 \%}$ yield over two steps. Compound $\mathbf{1 7}$ has been used previously by Olson and co-workers in their synthesis of (-)-roxifiban thus completing the formal synthesis of $\mathbf{1 8} .^{13}$

\section{Scheme 6. Formal Synthesis of Roxifiban ${ }^{a}$}

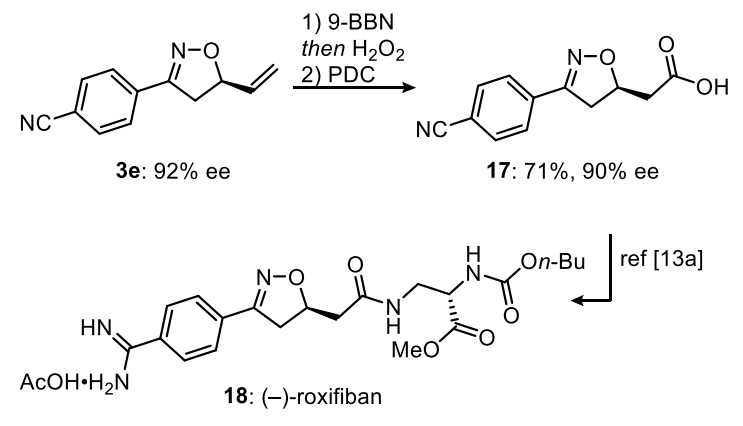

aReagents and conditions: (a) 9-BBN, THF then $\mathrm{H}_{2} \mathrm{O}_{2}$, aq. $\mathrm{NaOH}, \mathrm{THF} / \mathrm{H}_{2} \mathrm{O}(3: 1)$; (b) PDC, DMF.

The second synthetic endeavor was centered around the enantioselective tandem $N$-allylation/cycloaddition reaction established in Scheme 3. We identified (+)-halichlorine (19) as a suitable target to demonstrate the synthetic efficiency of the method to access the intriguing spirocyclic core structures (Scheme 7). (+)-Halichlorine was isolated from the marine sponge Halichondria okadai and was shown to possess interesting biological activities such as inhibition of the vascular cell adhesion molecule VCAM-1, which is of interest in the treatment of inflammatory diseases and in anti-cancer research. ${ }^{14}$

Racemic isoxazolidine $\mathbf{2 0}$ was prepared by the Stockman group ${ }^{31 c}$ to intercept a synthetic route towards halichlorine (via lactam 21) previously reported by Clive and co-workers. ${ }^{39}$ In pursuit of alcohol 20, we identified oxime $\mathbf{2 4}$ as a suitable starting material for the iridium catalyzed key step. The synthesis commenced with Grignard addition of $\mathbf{2 3}$ to racemic lactone $\mathbf{2 2 .} .^{40}$ Slow addition of $\mathbf{2 3}$ to a solution of lactone 22 at $-78^{\circ} \mathrm{C}$ followed by warming to $-30{ }^{\circ} \mathrm{C}$ allowed selective mono-addition of the organometallic reagent. After treatment with hydroxylamine hydrochloride, oxime $\mathbf{2 4}$ was isolated in $\mathbf{7 3 \%}$ yield over two steps. Iridium-catalyzed chemoselective $\mathrm{N}$-alkylation and thermal 1,3-dipolar cycloaddition cleanly afforded tricyclic isoxazolidine $\mathbf{2 5}$ bearing four stereogenic centers in $42 \%$ yield, $98 \%$ ee, and $18: 1 \mathrm{~d}$.r. on $2.5 \mathrm{mmol}$ scale. Isoxazolidine 25 was hydroborated and oxidized to the corresponding primary alcohol 26 in nearly quantitative yield using 9-BBN and $\mathrm{H}_{2} \mathrm{O}_{2} / \mathrm{NaOH}$. A sequence involving Ley oxidation, Pinnick oxidation and Steglich esterification provided access to ester $\mathbf{2 7}$ as a single diastereomer in $61 \%$ overall yield. Finally, cleavage of the silyl ether 
gave alcohol 20 in 91\% yield and completed the formal synthesis of (+)-halichlorine. Gratifyingly, SFC analysis confirmed that isoxazolidine $\mathbf{2 0}$ was formed without erosion of optical purity ( $98 \%$ ee).

Scheme 7. Formal Synthesis of (+)-Halichlorine ${ }^{a}$

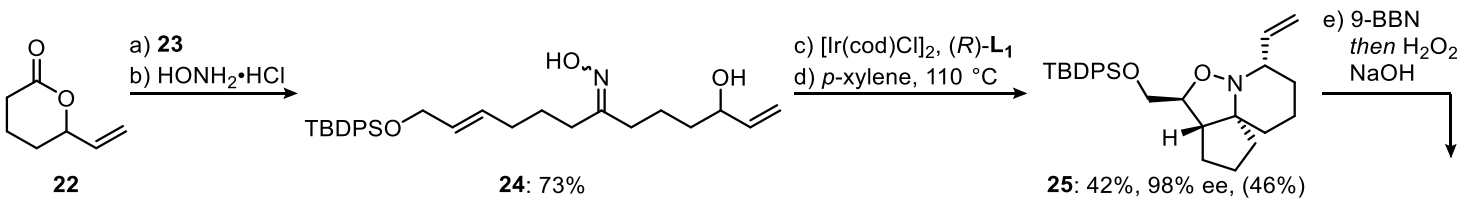

22

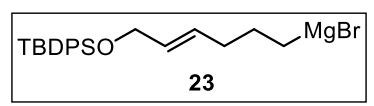

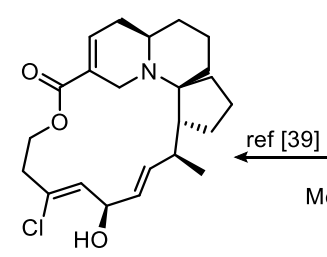

19: (+)-halichlorine
25: $42 \%, 98 \%$ ee, $(46 \%)$ $18: 1$ d.r.

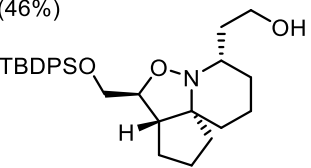

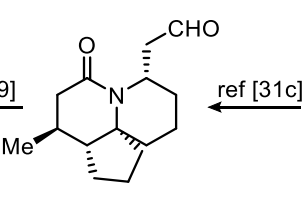

21

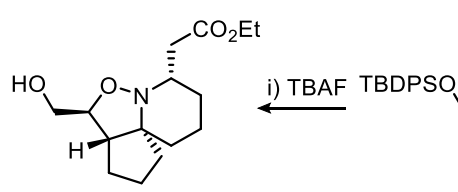

20: $91 \%, 98 \%$ ee

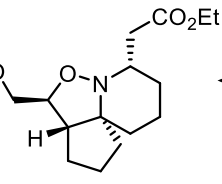

27: $61 \%$

${ }^{a}$ Reagents and conditions: (a) Grignard reagent $23, \mathrm{THF},-78$ to $-30{ }^{\circ} \mathrm{C}$; (b) hydroxylamine hydrochloride, pyridine, EtOH; (c) $[\operatorname{Ir}(\operatorname{cod}) \mathrm{Cl}]_{2}(3 \mathrm{~mol} \%),(R)-\mathrm{L}_{1}(12 \mathrm{~mol} \%), \mathrm{DCE}$, number in parentheses refers to recovered starting material; (d) $p$-xylene, $110{ }^{\circ} \mathrm{C} ;(\mathrm{e})$ 9-BBN, THF then $\mathrm{H}_{2} \mathrm{O}_{2}$, aq. $\mathrm{NaOH}, \mathrm{THF} / \mathrm{H}_{2} \mathrm{O}$ (3:1); (f) tetrapropylammonium perruthenate (TPAP), $\mathrm{N}$-methylmorpholine $\mathrm{N}$-oxide (NMO), $\mathrm{CH}_{2} \mathrm{Cl}_{2}$; (g) $\mathrm{NaClO}_{2}, \mathrm{NaH}_{2} \mathrm{PO}_{4}$, 2-methyl-2-butene, $t$ - $\mathrm{BuOH} / \mathrm{H}_{2} \mathrm{O}$ (3:1); (h) 1-ethyl-3-(3-dimethylaminopropyl)carbodiimide (EDCl), DMAP, EtOH, $\mathrm{CH}_{2} \mathrm{Cl}_{2}$; (i) $n-\mathrm{Bu}_{4} \mathrm{NF}$ (TBAF), THF.

Control Experiments. Over the course of this study we became interested in the origin of the remarkable chemoselectivity observed for both $\mathrm{N}$ - and $\mathrm{O}$-alkylation reactions. In particular, we wondered if the formation the cyclic nitrones or oxime ethers is governed by a thermodynamic bias and whether the size of the newly formed ring factors into this. The relative energies of two pairs of constitutionally isomeric nitrones and oxime ethers were calculated (2a/3a and $\mathbf{2 k} \mathbf{3} \mathbf{3 c}$, Scheme 8 ). Interestingly, density functional theory calculations at the B3PW91/6-311++G(d,p) level of theory revealed the nitrone products to be thermodynamically favored over the oxime ethers by $\Delta \Delta \mathrm{G}^{0}=5.0 \mathrm{kcalmol}^{-1}$ and $\Delta \Delta \mathrm{G}^{0}=5.7 \mathrm{kcalmol}^{-1}$, respectively, regardless of ring size. ${ }^{41,42} \mathrm{Notably}$, the calculated optimized geometry of 2-thienyl nitrone $\mathbf{2 k}$ was consistent with the conformation observed by X-ray crystallography (Table 2).

\section{Scheme 8. Calculated Optimized Structures and Relative Energies ${ }^{a}$}<smiles>C=C[C@H]1CCCC=[N+]1[O-]</smiles>
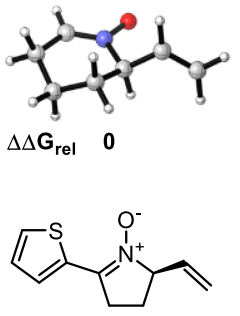

2k

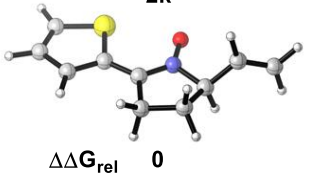<smiles>C=CC1CCCC=NO1</smiles>

$3 a$
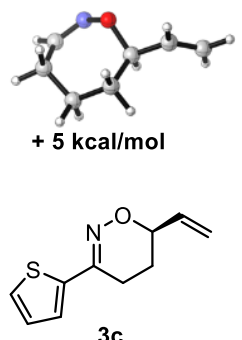

$3 c$

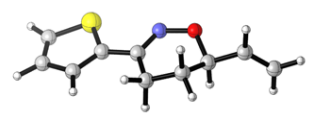

$+5.7 \mathrm{kcal} / \mathrm{mol}$

${ }^{a}$ Values calculated using DFT at the B3PW91/6-311++G(d,p) level of theory, see supporting information for details.

To probe whether the chemoselective formation of nitrone $\mathbf{2 a}$ may occur via thermodynamic equilibration from $\mathbf{3 a}$, we conducted a series of control experiments (Scheme 9). Subjecting racemic oxime ether 3a to the optimized reaction conditions for $N$ allylation afforded the corresponding nitrone $\mathbf{2 a}$. This result demonstrates that $\mathrm{C}-\mathrm{O}$ bond cleavage occurs for $\mathbf{3 a}$ in the presence of the iridium catalyst under acidic conditions. Control experiments indicated that both $\mathrm{Cl}_{2} \mathrm{CHCO}_{2} \mathrm{H}$ and $\left[\mathrm{Ir} /(\mathrm{S})\right.$ - $\left.\mathrm{L}_{1}\right]$ were necessary for conversion of $\mathbf{3 a}$ to give $\mathbf{2 a}$. Next, we investigated whether nitrone $\mathbf{2 a}$ undergoes reversible $\mathrm{C}-\mathrm{N}$ bond cleavage. Subjecting $\mathbf{2 a}$ to the conditions optimized for $\mathrm{O}$-alkylation did not afford any detectable formation of oxime ether $3 a$. Treating $2 \mathrm{a}$ with $\mathrm{Cl}_{2} \mathrm{CHCO}_{2} \mathrm{H}$ 
and the iridium catalysts derived from either $(R)-L_{1}$, the enantiomeric ligand, or achiral $\mathbf{L}_{3}$ did not lead to any erosion of optical purity, even after prolonged reaction times ( $48 \mathrm{hrs}$ ). Collectively, these experiments indicate that $\mathrm{C}-\mathrm{N}$ bond cleavage does not occur under basic nor acidic conditions. We postulate that while $O$-alkylated product 3 a may be formed under acidic conditions as the kinetic product, it can undergo $\mathrm{C}-\mathrm{O}$ bond cleavage to afford thermodynamically favored nitrone $2 \mathrm{a}$. The formation of oxime ether 3a under basic conditions is kinetically favored, as a consequence of deprotonation of the oxime-OH (pKa of benzophenone oxime in water 11). ${ }^{43}$ However, our observations with $\mathbf{2 a / 3 a}$ were not generalizable, as subjecting six membered oxime ether $\mathbf{3 c}$ to $\mathrm{Cl}_{2} \mathrm{CHCO}_{2} \mathrm{H} /[\mathrm{Ir}]$ did not lead to formation of nitrone $2 \mathrm{~m}$.

Scheme 9. Control experiments on $\mathrm{N} / \mathrm{O}$-alkylation ${ }^{a}$

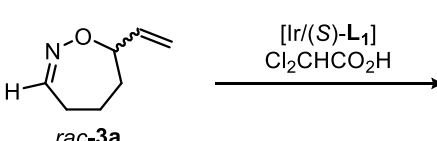

rac-3a<smiles>C=C[C@H]1CCCC=C1[O-]</smiles>

2a

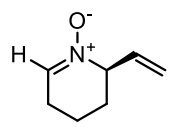

2a: $98 \%$ ee

[Ir/(S)- $\left.\mathrm{L}_{1}\right]$
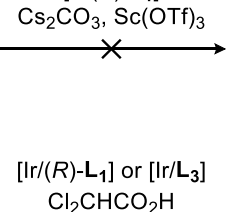

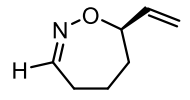

3a: not observed

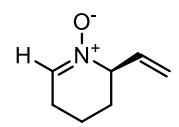

2a: recovered with $98 \%$ ee

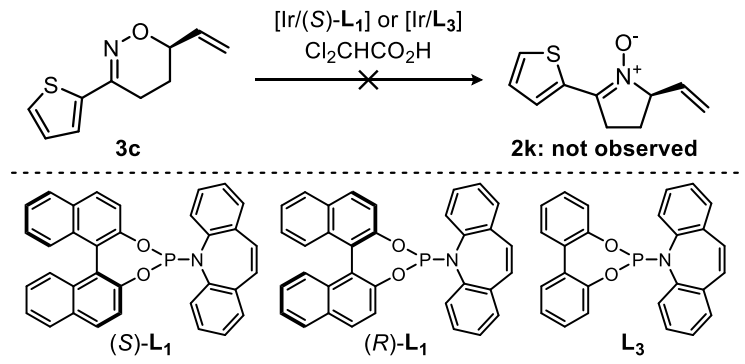

${ }^{a}$ Reactions were set up according to general procedures, see Tables 2 and 3.

It is worth noting that most of the oximes employed for nitrone formation are found as a mixture of $E / Z$ geometric isomers ranging from $1.5: 1$ to $1: 1$. Oximes $\mathbf{1} \mathbf{h}, \mathbf{1} \mathbf{n}$, and $\mathbf{1} \mathbf{q}$ are exceptions, as expected because of overwhelming steric biases inherent to the structures. Moreover, during the preparation of nitrone $\mathbf{2} \mathbf{b}$ under the catalytic, enantioselective conditions described, an aliquot was taken after 6 hours and analyzed by ${ }^{1} \mathrm{H}$ NMR spectroscopy. Analysis revealed at this point in time a 1:1 ratio of starting material to product as well as a 1:1 mixture of oxime $E / Z$-isomers, and each were then isolated in high enantiomeric purity (Scheme $10 \mathrm{~A}$ ). Additionally, for benzylic nitrone $\mathbf{2 e}$ all four stereoisomers of reisolated starting material $(S)-1 \mathbf{e}(E / Z=1: 1)$ were separated in one run on chiral HPLC, allowing confirmation that both oxime diastereomers had identical enantiomeric purities ( $98 \%$ ee, Scheme $10 \mathrm{~B}$ ). Collectively, these data suggest that $E$ and $Z$ oxime isomers interconvert rapidly under the reaction conditions, thus enabling highly efficient kinetic resolution of the allylic alcohols under Curtin-Hammet regimes. ${ }^{25}$ 

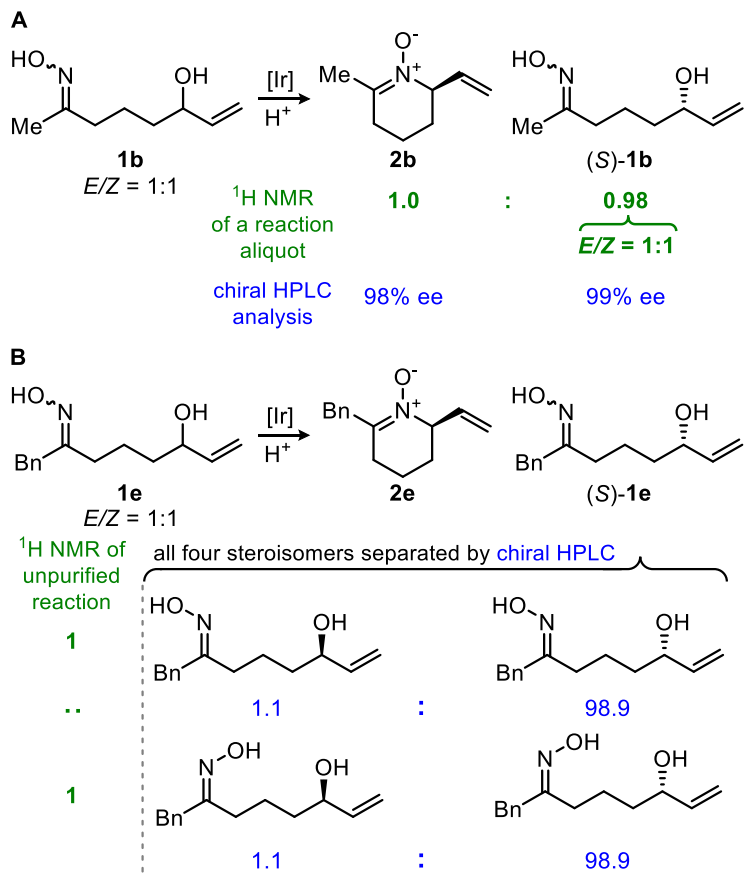

\section{Conclusions}

In summary, we have developed the highly enantio- and chemoselective iridium-catalyzed kinetic resolution of allylic alcohols via either $\mathrm{N}$ - or $\mathrm{O}$-allylation of oximes even when these starting materials are mixtures of $\mathrm{E} / \mathrm{Z}$ geometric isomers. The catalytic method provides for the first time convenient access to optically active cyclic nitrones and oxime ethers. The approach employs readily available mixtures of oximes $(E / Z)$ and allylic alcohols $(R$ and $S)$. We document for the first time entry into enantioselective tandem nitrone formation/1,3-dipolar cycloaddition cascades which are highly relevant for the asymmetric synthesis of complex molecules, as demonstrated by the efficient formal synthesis of the marine natural product (+)-halichlorine. We have also shown that enantio- and chemoselective $\mathrm{N}$-allylation can be expanded to the synthesis of optically active azomethine imines. Altogether, this methodology provides access to a diverse set of enantioenriched building blocks amenable to numerous further synthetic transformation and target-oriented synthesis. More broadly, the approach provides avenues for incorporating catalytic enantioselective process in cascading reactions that furnish complex structures in optically active form.

\section{Corresponding Author}

*E-mail: erickm.carreira@org.chem.ethz.ch

\section{ACKNOWLEDGMENT}

We are grateful to the ETH Zürich and the Swiss National Science Foundation (200020_172516) for financial support. Simon L. Rössler is thanked for carrying out DFT calculations. We also thank Dr. N. Trapp and M. Solar for X-ray crystallographic analyses.

\section{REFERENCES}

(1) (a) Fevig, T. L.; Bowen, S. M.; Janowick, D. A.; Jones, B. K.; Munson, H. R.; Ohlweiler, D. F.; Thomas, C. E. Design, Synthesis, and in Vitro Evaluation of Cyclic Nitrones as Free Radical Traps for the Treatment of Stroke. J. Med. Chem. 1996,39, 4988. (b) Dhainaut, A.; Tizot, A.; Raimbaud, E.; Lockhart, B.; Lestrage, P.; Goldstein, S. Synthesis, Structure, and Neuroprotective Properties of Novel Imidazolyl Nitrones. J. Med. Chem. 2ooo, 43, 2165. (c). Durand, G.; Polidori, A.; Salles, J.-P.; Pucci, B. Synthesis of a New Family of Glycolipidic Nitrones as Potential Antioxidant Drugs for Neurodegenerative Disorders. Bioorg. Med. Chem. Lett. 20o3, 13, 849. (d) Kolis, S. P.; Hansen, M. M.; Arslantas, E.; Brändli, L.; Buser, J.; DeBaillie, A. C.; Frederick, A. L.; Hoard, D. W.; Hollister, A.; Huber, D.; Kull, T.; Linder, R. J.; Martin, T. J.; Richey, R. N.; Stutz, A.; Waibel, M.; Ward, J. A.; Zamfir, A. Synthesis of BACE Inhibitor LY2886721. Part I. An Asymmetric Nitrone Cycloaddition Strategy Org. Process Res. Dev. 2015, 19, 1203. e) Kabala, K.; Grzeszczyk, B.; Stecko, S.; Furman, B.; Chmielewki, M. Approach to Monobactams and Nocardicins via Diastereoselective Kinugasa Reaction. J. Org. Chem. 2015, 8o, 12038.

(2) For a general review, see: (a) Nair, V.; Suja, T. D. Intramolecular 1,3-dipolar cycloaddition reactions in targeted syntheses. Tetrahedron 2007, 63, 12247. For selected examples, see: (b) Erhard, T.; Ehrlich, G.; Metz, P. A Total Synthesis of ( \pm )-Codeine by 1,3-Dipolar Cy 
cloaddition. Angew. Chem., Int. Ed. 2011, 50, 3892. (c) Lisnyak, V. G.; Lynch-Colameta, T.; Snyder, S. A. Mannich-type Reactions of Cyclic Nitrones: Effective Methods for the Enantioselective Synthesis of Piperidine-containing Alkaloids. Angew. Chem., Int. Ed. 2018, 57, 15162.

(3) (a) Wong, E. H. H.; Junkers, T.; Barner-Kowollik, C. Nitrones in synthetic polymer chemistry. Polym. Chem. 2011, 2, 10o8. (b) Gerengi, H.; Solomon, M. M.; Öztürtk, S.; Yildirim, A.; Gece, G. Evaluation of the Corrosion Inhibiting Efficacy of a Newly Synthesized Nitrone against St37 Steel Corrosion in Acidic Medium: Experimental and Theoretical Approaches. Materials Science E Engineering C 2018, 93, 539 .

(4) (a) Ning, X.; Temming, R. P.; Dommerholt, J.; Guo, J.; Ania, D. B.; Debets, M. F.; Wolfert, M. A.; Boons, G.-J.; van Delft, F. L. Protein Modification by Strain-Promoted Alkyne-Nitrone Cycloaddition. Angew. Chem., Int. Ed. 2010, 49, 2065. (b) McKay, C. S.; Blake, J. A.; Cheng, J.; Danielson, D. C.; Pezacki, J. P. Strain-Promoted Cycloadditions of Cyclic Nitrones with Cyclooctynes for Labeling Human Cancer Cells. Chem. Commun. 2o11, 47, 10040. (c) Sherratt, A. R.; Chigrinova, M.; MacKenzie, D. A.; Rastogi, N. K.; Ouattara, M. T. M.; Pezacki, A. T.; Pezacki, J. P. Dual Strain-Promoted Alkyne-Nitrone Cycloadditions for Simultaneous Labeling of Bacterial Peptidoglycans. Bioconjugate Chem. 2016, 27, 1222.

(5) For general reviews on nitrone synthesis and their synthetic applications, see: (a) Murahashi, S.-I.; Imada, Y. Synthesis and Transformations of Nitrones for Organic Synthesis. Chem. Rev. 2019, 199, 4684. (b) Anderson, L. L. Diverse Applications of Nitrones for the Synthesis of Heterocyclic Compounds. Asian J. Org. Chem. 2016, 5, 9. (c) Hamer, J.; Macaluso, A. Nitrones. Chem. Rev. 1964, 64, 473.

(6) For general reviews on nucleophilic additions to nitrones, see: (a) Lombardo, M.; Trombini, C. Nucleophilic Additions to Nitrones. Synthesis 20oo, 759. (b) Merino, P.; Franco, S.; Merchan, F. L.; Tejero, T. Nucleophilic Additions to Chiral Nitrones: New Approaches to Nitrogenated Compounds. Synlett. 2ooo, 442. For selected examples, see: (c) Huber, R.; Knierzinger, A.; Obrecht, J.-P.; Vasella, A. Nucleophilic Additions to N-Glycosylnitrones. Asymmetric Synthesis of $\alpha$-Aminophosphonic Acids. Helv. Chim. Acta. 1985, 68, 1730 (d) Dondoni, A.; Franco, S.; Merchán, F. L.; Merino, P.; Tejero, T. Stereocontrol by Diethylaluminum Chloride in the Addition of 2-Lithiofuran and $\mathrm{N}$-Methyl-2-Lithioimidazole to $\alpha$-Alkoxy Nitrones. Total Synthesis of 5-O-Carbamoylpolyoxamic Acid. Tetrahedron Lett. 1993, 34, 5479. (e) Fässler, R.; Frantz, D. E.; Oetiker, J.; Carreira, E. M. First Synthesis of Optically Pure Propargylic N-Hydroxylamines by Direct, Highly Diastereoselective Addition of Terminal Alkynes to Nitrones. Angew. Chem., Int. Ed .20o2, 41, 3054. (f) Murahashi, S.-I.; Imada, Y.; Kawakami, T.; Harada, K.; Yonemushi, Y.; Tomita, N. Enantioselective Addition of Ketene Silyl Acetals to Nitrones Catalyzed by Chiral Titanium Complexes. Synthesis of Optically Active $\beta$-Amino Acids. J. Am. Chem. Soc. 20o2, 124, 2888. (g) Phillips, E. M.; Reynolds, T. E.; Scheidt, K. A. Highly Diastereo- and Enantioselective Additions of Homoenolates to Nitrones Catalyzed by N-Heterocyclic Carbenes. J. Am. Chem. Soc. 20o8, 130, 2416. (h) Sakai, T.; Soeta, T.; Endo, K.; Fujinami, S.; Ukaji, Y. Magnesium-Tartramide Complex Mediated Asymmetric Strecker-Type Reaction of Nitrones Using Cyanohydrin. Org. Lett. 2o13, 15, 2422. (i) Murahashi, S.-I.; Tsuji, T.; Ito, S. Synthesis of Optically Active $\mathrm{N}$-Hydroxylamines by Asymmetric Hydrogenation of Nitrones with Iridium Catalysts. Chem. Commun. $2000,409$.

(7) Yao, Q.; Zabawa, M.; Woo, J.; Zhen, C. Carbocyclic Carbene Ligands Derived from Aromatic Nitrones: Formation and Catalytic Activity of Their Pd(II) Complexes. J. Am. Chem. Soc. 2007, 129, 3088. (b) Wang, C.; Wang, D.; Yan, H.; Wang, H.; Pan, B.; Xin, X.; Li, X.; $\mathrm{Wu}, \mathrm{F}$.; Wan, B. Rhodium-Catalyzed Cyclization of Diynes with Nitrones: A Formal $[2+2+5]$ Approach to Bridged Eight-Membered Heterocycles. Angew. Chem., Int. Ed. 2014, 53, 11940. (c) Dateer, R. B.; Chang, S. Selective Cyclization of Arylnitrones to Indolines under External Oxidant-Free Conditions: Dual Role of Rh(III) Catalyst in the C-H Activation and Oxygen Atom Transfer. J. Am. Chem. Soc. 2015, 137, 4908. (d) Pi, C.; Cui, X.; Wu, Y. Iridium-Catalyzed Direct C-H Sulfamidation of Aryl Nitrones with Sulfonyl Azides at Room Temperature. J. Org. Chem. 2015, 8o, 7333. (e) Bai, D.; Xu, T.; Ma, C.; Zhen, X.; Liu, B.; Xie, F.; Li; X. Rh(III)-Catalyzed Mild Coupling of Nitrones and Azomethine Imines with Alkylidenecyclopropanes via C-H Activation: Facile Access to Bridged Cycles. ACS Catal. $2018,8,4194$.

(8) For general reviews, see: (a) Gothelf, K. V.; Jørgensen, K. A. Asymmetric 1,3-Dipolar Cycloaddition Reactions. Chem. Rev. 1998, 98, 863. (b) Stanley, L. M.; Sibi, M. P. Enantioselective Copper-Catalyzed 1,3-Dipolar Cycloadditions. Chem. Rev. 20o8, 108, 2887. (c) Hashimoto, T.; Maruoka, K. Recent Advances of Catalytic Asymmetric 1,3-Dipolar Cycloadditions. Chem. Rev. $2015,115,5366$.

(9) Lo, M. M.-C.; Fu, G C. Cu(I)/Bis(azaferrocene)-Catalyzed Enantioselective Synthesis of $\beta$-Lactams via Couplings of Alkynes with Nitrones. J. Am. Chem. Soc. 2002, 124, 4572.

(10) Confalone, P. N.; Huie, E. M. The [3 + 2] nitrone-olefin cycloaddition reaction. Organic Reactions 1988, $36,1-173$.

(11) (a) Brandi, A.; Cardona, F.; Cicchi, S., Cordero, F. M.; Goti, A. [3+ 2] Dipolar Cycloadditions of Cyclic Nitrones with Alkenes. In Organic Reactions; Denmark, S. E: Ed.; John Wiley \& Sons, Inc.: Hoboken, 2017, Chapter 1. (b) Brandi, A.; Cardona, F.; Cicchi, S.; Cordero, F. M.; Goti, A. Stereocontrolled Cyclic Nitrone Cycloaddition Strategy for the Synthesis of Pyrrolizidine and Indolizidine Alkaloids. Chem. Eur. J. 2009, 15, 7808. (c) Revuelta, J.; Cicchi, S.; Goti, A.; Brandi, A. Enantiopure Cyclic Nitrones: A Useful Class of Building Blocks for Asymmetric Syntheses. Synthesis 2007, 485.

(12) (a) Tufariello, J. J.; Mullen, G. B. A Synthesis of dl-Cocaine Using Nitrone Intermediates. J. Am. Chem. Soc. 1978, 100, 3638. (b) Tufariello, J. J.; Mullen, G. B.; Tegeler, J. J.; Trybulski, E. J.; Wong, S. C.; Ali, S. A. Synthesis in the Tropane Class of Alkaloids. Pseudotropine and dl-Cocaine. J. Am. Chem. Soc. 1979, 101, 2435. (c) Karatholuvhu, M. S.; Sinclair, A.; Newton, A. F.; Alcaraz, M.-L.; Stockman, R. A.; Fuchs, P. L. A Concise Total Synthesis of DL-Histrionicotoxin. J. Am. Chem. Soc. 20o6, 128, 12656. (Error! Reference source not found.) (a) Zhang, M.; Liu, S.; Li, H.; Guo, Y.; Li, N.; Guan, M.; Mehfooz, H.; Zhou, J; Zhang, Q. Copper-Catalyzed Cope-Type Hydroamination of Nonactivated Olefins toward Cyclic Nitrones: Scope, Mechanism, and Enantioselective Process Development. Chem. Eur. J. 2019, 25, 12620. For one-pot approaches relying on organocatalytic enantioselective conjugate addition and reductive cyclization, see: (b) Sadaba, D.; Delso, I.; Tejero, T.; Merino; P. Water-Compatible One-Pot Organocatalytic Asymmetric Synthesis of Cyclic Nitrones. Application in Intramolecular 1,3-Dipolar Cycloadditions. Tetrahedron Lett. 2011, 52, 5976. (c) Mancheño, O. G., Tangen, P.; Rohlmann, R.; Fröhlich R.; Aleman, J. Synthesis of Chiral Cyclic Nitrones by Asymmetric Addition of $\beta$-Ketosulfones to Nitroalkenes followed by Reductive Cyclization Chem. Eur. J. 2011, 17, 984.

(13) Xue, C.-B.; Wityak, J.; Sielecki, T. M.; Pinto, D. J.; Batt, D. G.; G. A.; Cain; Sworin, M.; Rockwell, A. L.; Roderick, J. J.; Wang, S.; Orwat, M. J.; Frietze, W. E.; Bostrom, L. L.; Liu, J.; Higley, C. A.; Rankin, F. W.; Tobin, A. E.; Emmett, G; Lalka, G. K.; Sze, J. Y.; Di Meo, S. V.; Mousa, S. A.; Thoolen, M. J.; Racanelli, A. L. Hausner, E. A.; Reilly, T. M.; DeGrado, W. F.; Wexler, R. R.; Olson, R. E. Discovery of an Orally Active Series of Isoxazoline Glycoprotein IIb/IIIa Antagonists. J. Med. Chem. 1997, 40, 2064.

(14Error! Reference source not found.) (a) Kuramoto, M.; Tong, C.; Yamada; K.; Chiba, T.; Hayashi, Y.; Uemura, D. Halichlorine, an Inhibitor of VCAM-1 Induction from the Marine Sponge Halichondria okadai Kadota. Tetrahedron Lett. 1996, 37, 3867. (b) Arimoto, H.; Hayakawa, I.; Kuramoto, M.; Uemura, D. Absolute Stereochemistry of Halichlorine; A Potent Inhibitor of VCAM-1 Induction Tetrahedron Lett. 1998, 39, 861. 
(15) (a) Li, Z.; Zhao, J.; Sun, b.; Zhou, B.; Liu, M.; Zhang, M.; Zhang, Q. Asymmetric Nitrone Synthesis via Ligand-Enabled CopperCatalyzed Cope-Type Hydroamination of Cyclopropene with Oxime. J. Am. Chem. Soc. 2017, 139, 11702.

${ }^{(16)}$ Kitanosono, T.; Xu, P.; Kobayashi, S. Chiral Lewis Acids Integrated with Single-Walled Nanotubes for Asymmetric Catalysis in Water. Science 2018, 362, 311.

(17) Wang, Y.-H.; Breit, B. Chemo-, Regio-, and Enantioselective Synthesis of Allylic Nitrones via Rhodium-Catalyzed Addition of Oximes to Allenes. Chem. Commun. 2019, 55, 7619 .

(19) For general reviews on metal-catalyzed allylic substitution, see: (a) Halpern, J.; Trost, B. M. Asymmetric Catalysis. Proc. Natl. Acad. Sci. U. S. A. 2004, 101, 5347. (b) Trost, B. M.; Crawley, M. L. Asymmetric Transition-Metal-Catalyzed Allylic Alkylations: Applications in Total Synthesis. Chem. Rev. 2003, 103, 2921. (c) Stanley, L. M.; Hartwig, J. F. Mechanistically Driven Development of Iridium Catalysts for Asymmetric Allylic Substitution. Acc. Chem. Res. 2o10, 43, 1461 (d) Oliver, S.; Evans, P. A. Transition-Metal-Catalyzed Allylic Substitution Reactions: Stereoselective Construction of $\alpha$ - and $\beta$-Substituted Carbonyl Compounds. Synthesis 2013, 45, 3179. (e) Cheng, Q.; Tu, H.-F.; Zhen, C.; Qu, J.-P.; Helmchen, G.; You, S.-L. Iridium-Catalyzed Asymmetric Allylic Substitution Reactions. Chem. Rev. 2019, 119, 1855. For selected examples using Pd, Mo, and Rh, see: (f) Trost, B. M.; Van Vranken, D. L. Asymmetric Ligands for Transition-Metal-Catalyzed Reactions: 2-Diphenylphosphinobenzoyl Derivatives of C2-Symmetric Diols and Diamines. Angew. Chem. Int. Ed. 1992, 31, 229. (g) Trost, B. M.; Lautens, M Molybdenum Catalysts for Allylic Alkylation. J. Am. Chem. Soc. 1982, 104, 5543. (h) Turnbull, B. W. H.; Evans, P. A. Enantioselective Rhodium-Catalyzed Allylic Substitution with a Nitrile Anion: Construction of Acyclic Quaternary Carbon Stereogenic Centers. J. Am. Chem. Soc. 2015, 137, 6156.

(20) For a comprehensive account, see: (a) Rössler, S. L.; Petrone, D. A.; Carreira, E. M. Iridium-Catalyzed Asymmetric Synthesis of Functionally Rich Molecules Enabled by (Phosphoramidite,Olefin) Ligands. Acc. Chem. Res. 2019, 52, 2657. For relevant reactions using $O$ - and N-nucleophiles, see: (b) Defieber, C.; Ariger, M. A.; Moriel, P.; Carreira, E. M. Iridium-Catalyzed Synthesis of Primary Allylic Amines from Allylic Alcohols: Sulfamic Acid as Ammonia Equivalent. Angew. Chem., Int. Ed. 2007, 46, 3139. (c) Roggen, M.; Carreira, E. M. Enantioselective Allylic Etherification: Selective Coupling of Two Unactivated Alcohols. Angew. Chem., Int. Ed. 2o11, 50, 5568. (d) Lafrance, M. Roggen, M.; Carreira, E. M. Direct, Enantioselective Iridium-Catalyzed Allylic Amination of Racemic Allylic Alcohols. Angew. Chem., Int. Ed. 2012, 51, 3470. (e) Hamilton, J. Y.; Rössler, S. L.; Carreira, E. M. Enantio- and Diastereoselective Spiroketalization Catalyzed by Chiral Iridium Complex. J. Am. Chem. Soc. 2017, 139, 8082. (f) Sandmeier, T.; Goetzke, F. W.; Krautwald, S.; Carreira, E. M. Iridium-Catalyzed Enantioselective Allylic Substitution with Aqueous Solutions of Nucleophiles. J. Am. Chem. Soc. 2019, 141, 12212.

(21) (a) Park, K.; Lagaditis, P. O.; Lough, A. J.; Morris, R. H. Synthesis of New Late Transition Metal P,P-, P,N-, and P,O- Complexes Using Phosphonium Dimers as Convenient Ligand Precursors. Inorg. Chem. 2o13, 52, 5448. (b) Watanabe, M.; Kashiwame, Y.; Kuwata, S.; Ikariya, T. Synthesis, Structures, and Transfer Hydrogenation Catalysis of Bifunctional Iridium Complexes Bearing a C-N Chelate Oxime Ligand. Eur. J. Inorg. Chem. 2012, 504. (c) Palepu, N. R.; Adhikari, S.; Premukar J, R.; Verma, A. K.; Shepherd, S. L.; Phillips, R. M.; Kaminsky, W.; Kollipara, M. R. Half-sandwich ruthenium, rhodium and iridium complexes featuring oxime ligands: Structural studies and preliminary investigation of in vitro and in vivo anti-tumour activities. Appl. Organomet. Chem. 2017, 31, e3640

(22) For the first definition of the term "ambident", see: (a) Kornblum, N.; Smiley, R. A.; Blackwood, R. K.; Iffland, D. C The Mechanism of the Reaction of Silver Nitrite with Alkyl Halides. The Contrasting Reactions of Silver and Alkali Metal Salts with Alkyl Halides. The Alkylation of Ambident Anions. J. Am. Chem. Soc. 1955, 77, 6269. For a recent review on ambident reactivity, see: (b) Mayr, H.; Breugst, M.; Ofial, A. R. Farewell to the HSAB Treatment of Ambident Reactivity. Angew. Chem., Int. Ed. 2011, 50, 6470. For an early example discussing the ambident character of oximes, see: (c) Smith, P. A. S.; Robertson, J. E. Some Factors Affecting the Site of Alkylation of Oxime Salts. J. Am. Chem. Soc. 1962, 84, 1197.

(23) For examples of competing $N$-vs $O$-functionalization, see: (a) Shatzmiller, S.; Shalom, E. Synthese und Thermischer Zerfall von OAlkyl-N-vinylhydroxylamin-Derivaten. Liebigs Ann. Chem. 1983, 897. (b) Grigg, R.; Hadjisoteriou, M.; Kennewell, P.; Markandu, J. Phenylselenyl Halide Induced Formation of Cyclic Nitrones from Alkenyl Oximes. J. Chem. Soc., Chem. Commun. 1992, 1537. (c) Tiecco, M.; Testaferri, L; Bagnoli, L.; Purgatorio, V.; Temperini, A.; Marini, F.; Santi, C. Efficient Asymmetric Selenocyclizations of Alkenyl Oximes into Cyclic Nitrones and 1,2-Oxazines Promoted by Sulfur Containing Diselenides. Tetrahedron Asymmetry, 20o1, 12, 3297. (d) Kurbanl1, S.; Şen, N.; Güler, E.; Koçak, A. The Investigation of the Alkylation Reactions of Hydroxy and En-Oximes with Some Halohydrins and Epoxides. Synth. Commun. 2004, 34, 1663. (e) Miyabe, H.; Yoshida, K.; Reddy, V. K.; Matsumura, A.; Takemoto, Y. Selective Synthesis of Allylated Oxime Ethers and Nitrones Based on Palladium-Catalyzed Allylic Substitution of Oximes. J. Org. Chem. 2005, 70, 5630. (f) Ahn, J. H.; Shin, M. S.; Jung, S. H.; Kim, J. A.; Kim, H. M.; Kim, S. H.; Kang, S. K.; Kim, K. R.; Rhee, S. D.; Park, S. D.; Lee, J. M.; Lee, J. H.; Cheon, H. G.; Kim, S. S. Synthesis and Structure-Activity Relationship of Novel Indene N-Oxide Derivatives as Potent Peroxisome Proliferator Activated Receptor $\gamma$ (PPAR $\gamma$ ) Agonists Bioorog. Med. Chem. Lett. 2007, 17, 5239. (g) Sin, N.; Venables, B. L.; Liu, X.; Huang, S.; Gao; Q.; Ng, A.; Daltero, R.; Rajamani, R.; Meanwell, N. A. The Alkylation of Isatin-Derived Oximes: Spectroscopic and X-Ray Crystallographic Structural Characterization of Oxime and Nitrone Products. J. Heterocyclic Chem. 2009, 46, 432. (h) Ma, X.-P.; Shi, W.-M.; Mo, X.-L.; Li, X.-L.; Li, X.-H.; Li, L.-G.; Pan, C.-X.; Chen, B.; Su, G.-F.; Mo, D.-L. Synthesis of $\alpha, \beta$-Unsaturated N-Aryl Ketonitrones from Oximes and Diaryliodonium Salts: Observation of a Metal-Free N-Arylation Process. J. Org. Chem. 2015, 8o, 10098.

(24) (a) Mandolini, L.; Illuminati, G. Ring Closure Reactions of Bifunctional Chain Molecules. Acc. Chem. Res. 1981, 14, 95. (b) Agapito, F.; Nunes, P. M.; Costa Cabral, B. J.; Borges dos Santos, R. M.; Martinho Simões, J. A. Energetic Differences between the Five- and SixMembered Ring Hydrocarbons: Strain Energies in the Parent and Radical Molecules. J. Org. Chem. 2oo8, 73, 6213.

(25) Seeman, J. I. Effect of conformational change on reactivity in organic chemistry. Evaluations, applications, and extensions of CurtinHammett Winstein-Holness kinetics Chem. Rev. 1983, 83, 83.

(26) (a) O'Ferrall, R. A. M.; O'Brien, D. Rate and equilibrium constants for hydrolysis and isomerization of $(E)$ - and $(Z)$-p-methoxybenzaldehydeoximes. J. Phys. Org. Chem. 2004, 17, 631. (b) Nsikabaka, S.; Harb, W.; Ruiz-López, M. F. The Role of Water on the Acid-Promoted E/Z Isomerization of Oximes in Aqueous Solution. J. Mol. Sturct. Theochem 2oo6, 764, 161. (c) Baláž, M.; Kudličková, Z.; Vilková, M.; Imrich, J.; Balážová, J.; Daneu, N. Mechanochemical Synthesis and Isomerization of $\mathrm{N}$-Substituted Indole-3-carboxaldehyde Oximes. Molecules 2019, 24, 3347 .

(27) For recent examples see: (b) Gärtner, M.; Jäkel, M.; Achatz, M.; Sonnenschein, C.; Tverskoy, O.; Helmchen, G. Enantioselective iridium-catalyzed allylic substitutions with hydroxamic acid derivatives as $N$-nulceophiles. Org. Lett. 2011, 13, 2810. (c) Gärtner, M.; Mader, S.; Seehafer, K.; Helmchen, G. Enantio- and regioselective iridium-catalyzed allylic hydroxylation. J. Am. Chem. Soc. 2011, 133, 2072. (d) Liu, W.-B.; Reeves, C. M.; Virgil, S. C.; Stoltz, B. M. Construction of Vicinal Tertiary and All-Carbon Quaternary Stereocenters via Ir- 
Catalyzed Regio-, Diastereo- ${ }^{-}$, and Enantioselective Allylic Alkylation and Applications in Sequential Pd Catalysis. J. Am. Chem. Soc. 2o13, 135, 10626. (e) Hethcox, J. C.; Shockley, S. E.; Stoltz, B. M. Iridium-CatalyzedStereoselectiveAllylic Alkylation Reactions with Crotyl Chloride. Angew. Chem., Int. Ed. 2016, 55, 16092. (f) Butcher, T. W.; Hartwig, J. F. Enantioselective Synthesis of Tertiary Allylic Fluorides by Iridium-Catalyzed Allylic Fluoroalkylation. Angew. Chem., Int. Ed. 2018, 57, 13125. (g) Yang, Z.-P.; Jiang, R.; Wu, Q.-F.; Huang, L.; Zheng, C.; You, S.-Y. Iridium-Catalyzed Intramolecular Asymmetric Allylic Dearomatization of Benzene Derivatives. Angew. Chem., Int. Ed. 2018, 57, 1519o. (h) Yang, Z.-P.; Jiang, R.; Zheng, C.; You, S.-Y. Iridium-Catalyzed Intramolecular Asymmetric Allylic Alkylation of Hydroxyquinolines: Simultaneous Weakening of the Aromaticity of Two Consecutive Aromatic Rings. J. Am. Chem. Soc. 2018, 140, 3114. (i) He, Z.-T.; Jiang, X.; Hartwig, J. F. Stereodivergent Construction of Tertiary Fluorides in Vicinal Stereogenic Pairs by Allylic Substitution with Iridium and Copper Catalysts. J. Am. Chem. Soc. 2019, 141, 13066.

(28) A similar observation was made by Shu-Li You and co-workers during their study on the Ir-catalyzed $O$-allylation of ketones and aldehydes. Wang, Y.; Zhang, W.-Y.; You, S.-L. Ketones and Aldehydes as O-Nucleophiles in Iridium-Catalyzed Intramolecular Asymmetric Allylic Substitution Reaction. J. Am. Chem. Soc. 2019, 141, 2228.

(29) s-Factors were calculated as described by Kagan and co-workers: Kagan, H. B.; Fiaud, J. C. Kinetic Resolution Top. Stereochem. 1988, 18, 249. Supporing Information of details.

(30) (a) Grigg, R.; Markandu, J.; Surendrakumar, S.; Thorton-Pett, M.; Warnock, W. J. X=Y-ZH Systems as Potential 1,3=Dipoles. Part 37 Generation of Nitrones from Oximes. Tandem Intramolecular 1,3-Azaprotio Cyclotransfer - Intrarholecular 1,3=Dipolar Cycloaddition Reactions. Class 4 Processes. Tetrahedron, 1992, 48, 10399. (b) Dondas, H. A.; Grigg, R.; Hadjisoteriou, M.; Markandu, J.; Thomas, W. A.; Kennewell, P. X=Y-ZH Systems as Potential 1,3-Dipoles. Part 50:1Phenylselenyl Halide Induced Formation of Cyclic Nitronesfrom Alkenyl Oximes. Tetrahedron, 2000, 56, 10087.

(31) (a) Stockman, R. A. Two-directional synthesis. Part 1: A short formal synthesis of ( \pm )-histrionicotoxin and ( \pm )-histrionicotoxin 235A. Tetrahedron Lett. 2ooo, 41, 9163. (b) Stockman, R. A.; Sinclair, A.; Arini, L. G.; Szeto, P.; Hughes, D. L. A Two-Directional Synthesis of ( \pm )Perhydrohistrionicotoxin J. Org. Chem. 2004, 69, 1598. (c) Gignoux, C.; Newton, A. F.; Barthelme, A.; Lewis, W.; Alcaraz, M.-L.; Stockman, R. A. Combining Two-Directional Synthesis and Tandem Reactions: A Short Formal Synthesis of Halichlorin. Org. Biomol. Chem. 2012, 10, 67.

(32) (a) Coldham, I.; Burrell, A. J. M.; White, L. E.; Adams, H.; Oram, N. Highly Efficient Synthesis of Tricyclic Amines by a Cyclization/Cycloaddition Cascade: Total Syntheses of Aspidospermine, Aspidospermidine, and Quebrachamine. Angew. Chem., Int. Ed. 20o7, 46, 6159. (b) Burrell, A. J. M.; Coldham, I.; Watson, L.; Oram, N.; Pilgram, C. D.; Martin, N. G. Stereoselective Formation of Fused Tricyclic Amines from Acyclic Aldehydes by a Cascade Process Involving Condensation, Cyclization, and Dipolar Cycloaddition. J. Org. Chem. 2oog, 74, 2290.

(33) For related work based on nitronate itnermediates, see: (a) Denmark, S. E.; Thorarensen, A. Tandem [4+2]/[3+2] Cycloadditions of Nitroalkenes. Chem. Rev. 1996, 96, 137. (b) Denmark, S. E.; Cramer, C. J.; Sternberg, J. A. Intermolecular [4 + 2]-Cycloadditions of Nitroalkenes with Cyclic Olefins. Transformations of Cyclic Nitronates. Helv. Chim. Acta. 1986, 69, 1971. (c) Denmark, S. E.; Moon, Y.-C.; Senanayake, C. B. W. Tandem [4+2]/[3+2] Cycloadditions: Facile and Stereoselective Construction of Polycyclic Frameworks. J. Am. Chem. Soc. 1990, 112, 311.

(34) For general reviews, see: (a) Sukhorukov, A. Y; Ioffe, S. L. Chemistry of Six-Membered Cyclic Oxime Ethers. Application in theSynthesis of Bioactive Compounds. Chem. Rev. 2011, 111, 5004. (b) Agrawal, N.; Mishra, P. The Synthetic and Therapeutic Expedition of Isoxazole and its Analogs. Med. Chem. Res. 2018, 27, 1309. (c) Kaur, K.; Kumar, V.; Sharma, A. K.; Gupta, G. K. Isoxazoline containing natural products as anticancer agents: A review. Eur. J. Med. Chem. 2014, 77, 121. (d) Lamberth, C. Oxazole and Isoxazole Chemistry in Crop Protection. J. Heterocycl. Chem. 2018, 55, 2035. (e) Mirjafary, Z.; Abdoli, M.; Saeidian, H.; Kakanejadifard, A.; Farina, S. M. F. Review on the Synthesis of Acyclic and Cyclic Oxime Ethers. RSC Adv. 2016, 6, 17740. For the iridium-catalyzed intermolecular allylation $O$-allylation of oximes, see: (f) Miyabe, H.; Matsumura, A.; Moriyama, K.; Takemoto, Y. Utility of the Iridium Complex of the Pybox Ligand in Regioand Enantioselective Allylic Substitution. Org. Lett. 2oo4, 6, 4631. (g) Miyabe, H.; Matsumura, A.; Yoshida, K.; Takemoto, Y. Synthesis of chiral oxime ethers based on regio- and enantioselective allylic substitution catalyzed by iridium-pybox complex. Tetrahedron. 20o9, 65 , 4464. For a recent method relying on Pd-catalyzed carboetherification, see: (h) Li, N.; Sun, B.; Zhao, J.; Zhang, Q. Highly Enantioselective Construction of Dihydrooxazines via Pd-Catalyzed Asymmetric Carboetherification. Org. Lett. 202o, 22, 190.

(35) For related, racemic cyclizations, see: (a) Guerrand, H. D. S.; Adams, H.; Coldham, I. Cascade Cyclization, Dipolar Cycloaddition of Azomethine Imines for the Synthesis of Pyrazolidines. Org. Biomol. Chem. 2o11, 9, 7921. (b) Hunt, A. D.; Dion, I.; Das Neves, N.; Taing, S.; Beauchemin, A. M. Synthesis of Azomethine Imines Using an Intramolecular Alkyne Hydrohydrazination Approach. J. Org. Chem. 2013, 78, 8847. (c) Beauchemin, A. M. Recent developments in Cope-type hydroaminationreactions of hydroxylamine and hydrazine derivatives. Org. Biomol. Chem. 2013, 117039.

(36) (a) Zhu, G. D.; Arendsen, D. L.; Gunawardana, I. W.; Boyd, S. A.; Stewart, A. O.; Fry, D. G.; Cool, B. L.; Kifle, L. Schaefer, V.; Meuth, J.; Marsh, K. C.; Kempf-Grote, A. J.; Kilgannon, P.; Gallatin, W. M.; Okasinski, G. F.; Selective Inhibition of ICAM-1 and E-Selectin Expression in Human Endothelial Cells. 2. Aryl Modifications of 4-(Aryloxy)thieno[2,3-c]pyridines with Fine-Tuning at C-2 Carbamides. J. Med. Chem. 2oo1, 44, 3469. (b) Kawakubo, H.; Okazaki, K.; Nagatani, T.; Takao, K.; Hasimoto, S.; Sugihara, T. Potent anticonflict activity and lessening of memory impairment with a series of novel [1] benzothieno[2,3-c]pyridines and 1,2,3,4-tetrahydro[1] benzothieno[2,3-c]pyridines. J. Med. Chem. 1990, 33, 3110.

(37) For literature precedence including a model for the stereochemical outcome, see: Reissing, H. U.; Hippeli, C. Chem. Ber. 1991, 124, 115.

(38) For the pharmacological activity of roxifiban, see: (a) Serebruany, V. L.; Malinin, A. I.; O'Connor, C. M.; Gurbel, P. A. Effects of Roxifiban on Platelet Aggregation and Major Receptor Expression in Patients with Coronary Artery Disease for the Roxifiban Oral Compound Kinetics Evaluation Trial-I (ROCKET-I Platelet Substudy). Am. Heart J. 20o3, 146, 91. (b) Murphy, J.; Wright, R. S.; Gussak, I.; Williams, B.; Daly, R. N.; Cain, V. A.; Pieniaszek, H. J.; Sy, S. K. B.; Ebling, W.; Simonson, K.; Wilcox, R. A.; Kopecky, S. L. The Use of Roxifiban (DMP754), a Novel OralPlatelet Glycoprotein IIb/IIIa Receptor Inhibitor,in Patients with Stable Coronary Artery Disease. Am. J. Cardiovasc. Drugs 2003, 3, 101. (c) Mousa, S. A.; Bozarth, J. M.; Naik, U. P.; Slee, A. Platelet GPIIb/IIIa binding characteristics of small molecule RGD mimetic: distinct binding profile for Roxifiban. Br. J. Pharmacol. 2oo9, 133, 331. 
(39) Liu, D.; Acharya, H. P.; Yu, M.; Wang, J.; Yeh, V. S. C.; Kang, S.; Chiruta, C.; Jachak, S. M.; Clive, D. L. J. Total Synthesis of the Marine Alkaloid Halichlorine: Development and Use of a General Route to Chiral Piperidines. J. Org. Chem. 20o9, 74, 7417.

(40) Bischop, M.; Pietruszka, J. Synthesis of vinyllactones via allylic oxidation of alkenoic acids. Synlett 2011, 2689.

(41) See Supporting Information for details.

(42) (a) R. Krishnan, R.; Binkley, J. S.; Seeger, R.; Pople, J. A. Self-consistent molecular orbital methods. XX. A basis set for correlated wave functions. J. Chem. Phys.,1980, 72, 650. (b) MacLean, A. D.; Chandler, G. S. Contracted Gaussian basis sets for molecular calculations. I. Second row atoms, $\mathrm{Z}=11-18$. J. Chem. Phys. 1980, 72, 5639. (c) DFT calculations were done with the Gaussian software package: Firsch, J. M. et al. Gaussian o9, revision D.o1, Gaussian, Inc., Wallingford CT, 2013.

(43) Roca-López, D.; Darù, A.; Tejeroa, T.; Merino, P. Revisiting Oxime-Nitrone Tautomerism. Evidence of Nitrone Tautomer Participation in Oxime Nucleophilic Addition Reactions. RSC Adv. 2016, 6, 22161. 

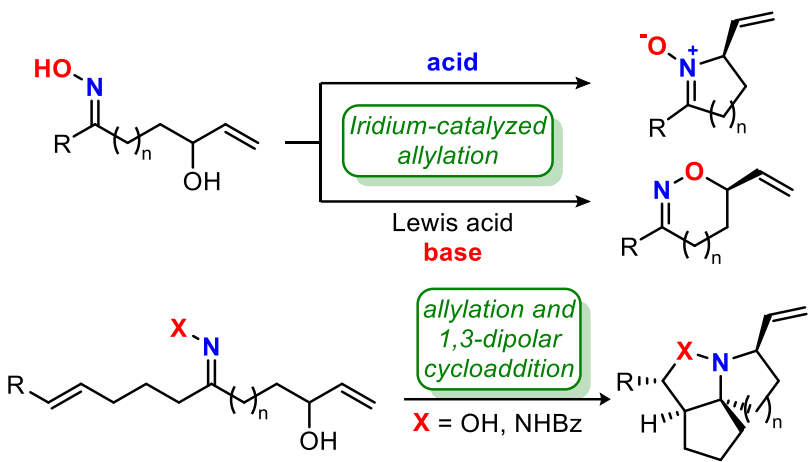

Insert Table of Contents artwork here 